\title{
21. TRIAXIAL COMPRESSION TESTS, LEG 20, DEEP SEA DRILLING PROJECT
}

\author{
Michael B. Smith, Mechanical Engineering Department, Rice University, Houston, Texas \\ and \\ George Z. Forristall, Shell Development Company, Houston, Texas
}

The mechanical strength of representative samples of lithified materials collected during Leg 20 was investigated in triaxial compression tests. An account of the philosophy behind the tests and the standard methods employed may be found in Hardin (1966), but a brief description of our procedures follows.

The tests are not truly triaxial, since two of the applied principal stresses are equal, being applied through a fluid confining pressure. The third principal stress is then increased with a mechanical piston while maintaining the confinind pressure, and thus the other two principal stresses, constant. Depending on the size of the sample collected, it was possible to cut from it one, two, or three 1/2-inch diameter by 1 -inch long cylinders for testing. Rather than repeating tests at the same confining pressure, we elected to test at various pressures so that a Mohr envelope of failure could be constructed. Although this philosophy probably succeeded in extracting the maximum information from the limited amount of sample material, it was rather frustrating when a test gave unexpected results and could not be repeated.

To isolate the cut samples from the working fluid, they were sheathed in Tygon tubing before being placed in the pressure vessel. This procedure also results in the sample pore pressure remaining atmospheric, a condition almost assuredly not true 6000 meters below the surface of the sea. However, by Terzaghi's (1943) well-documented concept of effective stress, increasing the pore pressure merely decreases the effective confining pressure by a like amount. Thus, effectively the same information about the rock properties is found by tests at any pore pressure, and since we had only a limited amount of sample material, we only made tests with atmospheric pore pressure.

The results of the test are presented in the accompanying table and Figures 1 through 8 . In each figure, the upper graph gives stress versus strain for various values of the confining pressure. The stress plotted is actually the differential stress, or axial stress minus confining pressure. The lower graphs give Mohr envelopes for the ultimate strength of the rock, where the stresses used in drawing the Mohr circles were the confining pressure and the maximum axial stress on the sample. In those cases where the sample was still strain hardening at the termination of the test, the stress at 25 percent strain was used instead of the maximum stress.

The notes in the table of mechanical properties refer to anomalous behavior observed during the tests. Some more detailed observations follow. Sample 199-10-2, No. 12 failed under hydrostatic load. Hydrostatic pressure was being applied in order to test the sample at a confining pressure of $10,000 \mathrm{psi}$; when the pressure was approximately $6000 \mathrm{psi}$, the sample failed. This result was unexpected and consequently, accurate measurements were not obtained. Another sample was prepared, the the hydrostatic pressure was applied much more slowly. When the pressure reached 9800 psi, cracking sounds were heard and the pressure dropped to $8000 \mathrm{psi}$. The pressure was then increased to $10,000 \mathrm{psi}$, but when the axial load was increased, the sample deformed as though it were perfectly plastic. Actually, it is more likely that the sample fractured completely when the confining pressure dropped.

Some attention should also be given to Samples 199-10-2, No. 2 and 197-1-1, Nos. 19 and 10, which were included together since they were petrologically similar basalts. Sample 197-1-1, No. 10 appeared to fracture at approximately 13 percent strain with $\sigma=38,095$ psi. It then recovered and seemed to start strain hardening again. Sample 199-10-2, No. 22 (Figure 5) exhibited the same behavior at 2 percent strain with $\sigma=32,275$ psi. Very distinct cracking sounds were also heard at this point, but this sample also recovered and continued to strain harden. It is possible that in both cases the samples fractured but were held together by the confining pressure and the apparent strength of the rock was due to external friction between the fractured pieces. Examination of the samples supported this theory but was not conclusive.

Sample 199-11-2, No. 60 is interesting due to its almost perfectly. plastic behavior (particularly at a confining pressure of $5000 \mathrm{psi})$.

Sample 202-3(CC), No. 14 was very weak and brittle at both atmospheric and 5000 psi confining pressures. This result at a confining pressure of 5000 psi was very unusual and further testing would need to be done to confirm it. For this reason the Mohr's circle at 5000 psi is not included in the Mohr envelope in Figure 8. For a confining pressure of $10,000 \mathrm{psi}$, the stress increased elastically and the sample then appeared to yield at $\sigma=8100 \mathrm{psi}$ and 2 percent strain. The stress then began to decrease as the strain increased. When the test was terminated, the sample had extruded through a small hole in the piston supplying the axial load. It is possible that instead of yielding plastically at $\sigma=8100$ psi, the sample fractured and the strength measured after that point was just the force required to extrude the sample. To check the results, further testing would be needed with the sample constrained not to extrude.

Figures 9 through 14 are photographs of some samples after testing, showing typical modes of failure. At atmospheric pressure the typical mode of failure is a brittle extension fracture, which is separation on a plane normal to the least principal stress. Figures 9 and 10, respectively, show limestone and basalt tested at atmospheric confining pressure, and we see that the fracture planes are roughly parallel to the axis of the test cylinder.

When the confining pressure is increased, failure is more likely to take place as faulting on planes inclined to the principal stress directions. This situation is illustrated in 

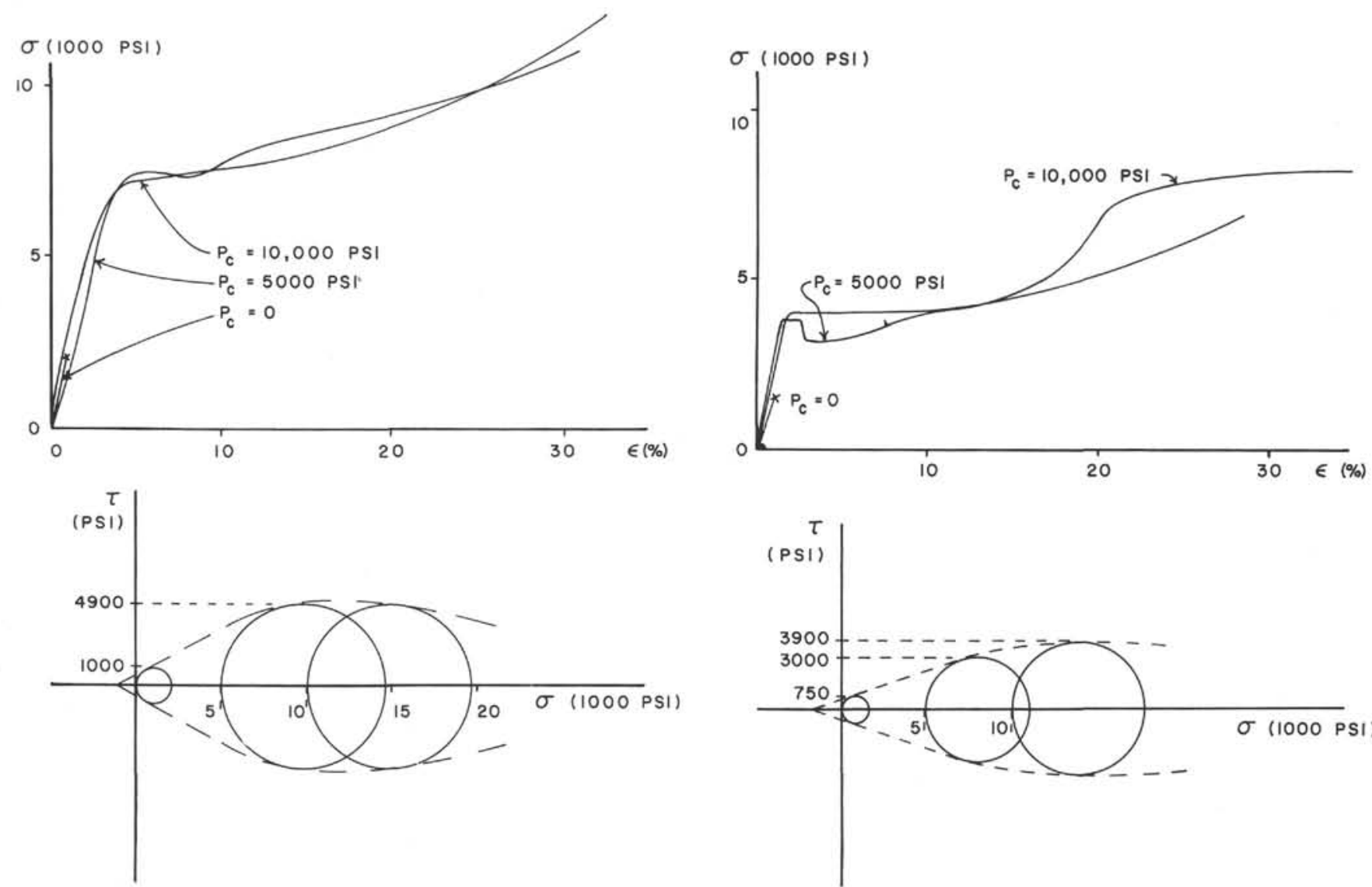

Figure 1. Stress-strain curves, Sample No, 199-7-1, No. 1.

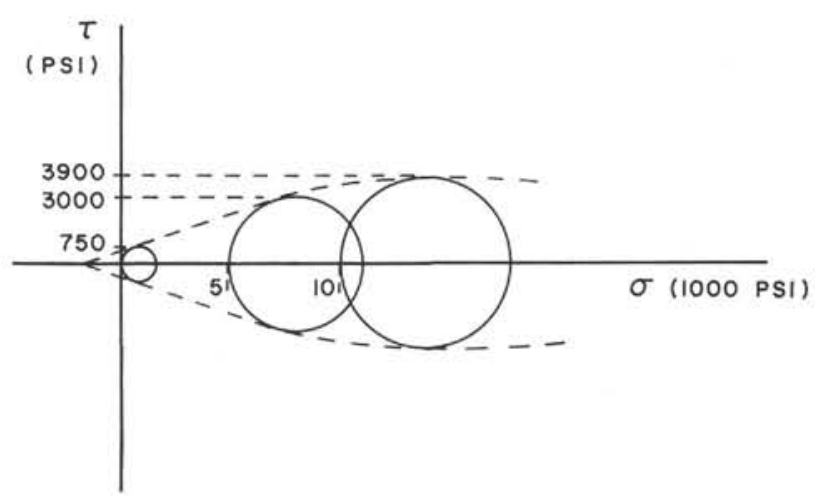

Figure 3. Stress-strain curves, Sample No. 199-9-2, No. 13.
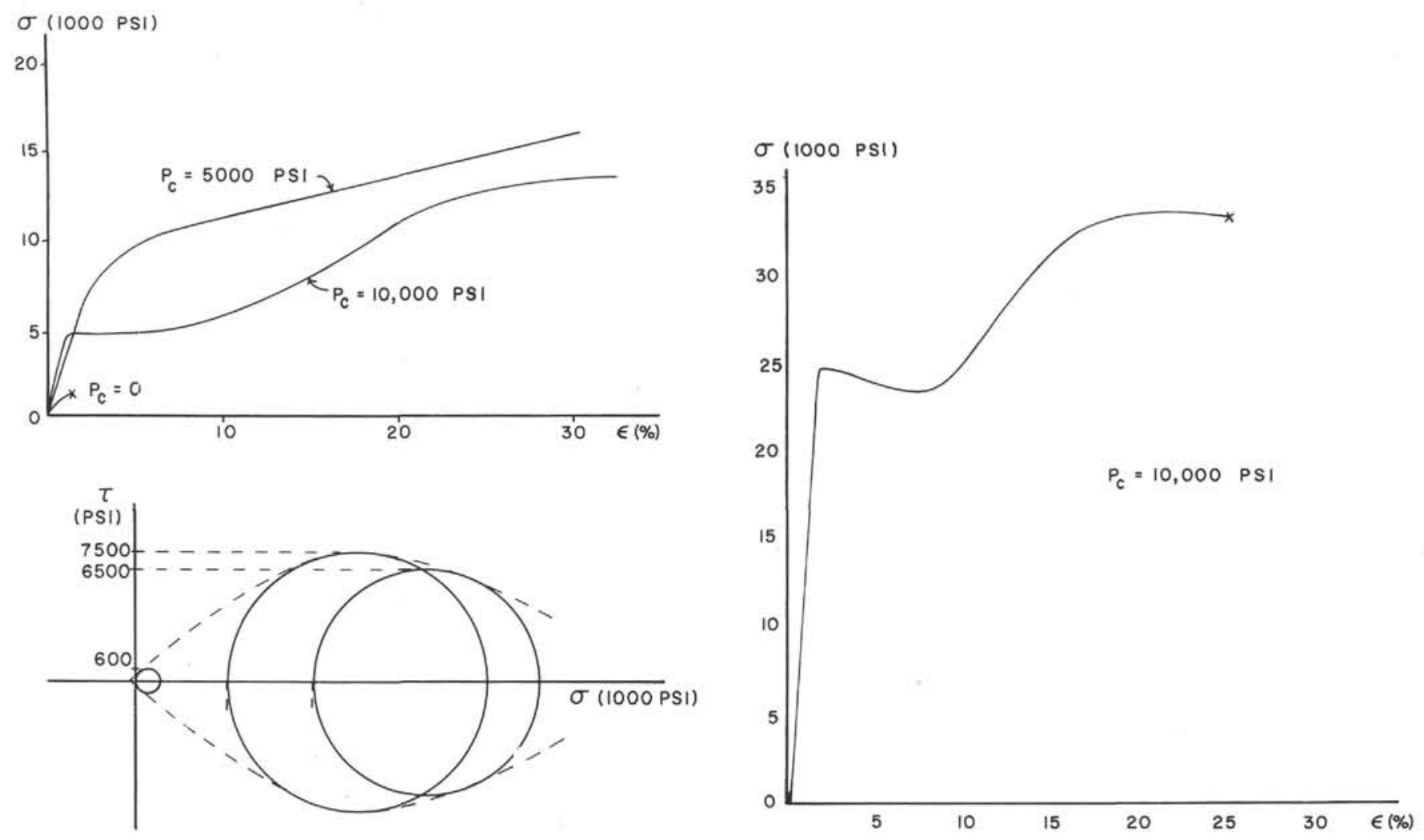

Figure 2. Stress-strain curves, Sample No, 196-3-1, No. 7 tan.

Figure 4. Stress-strain curves, Sample No. 195-3-1, brown. 

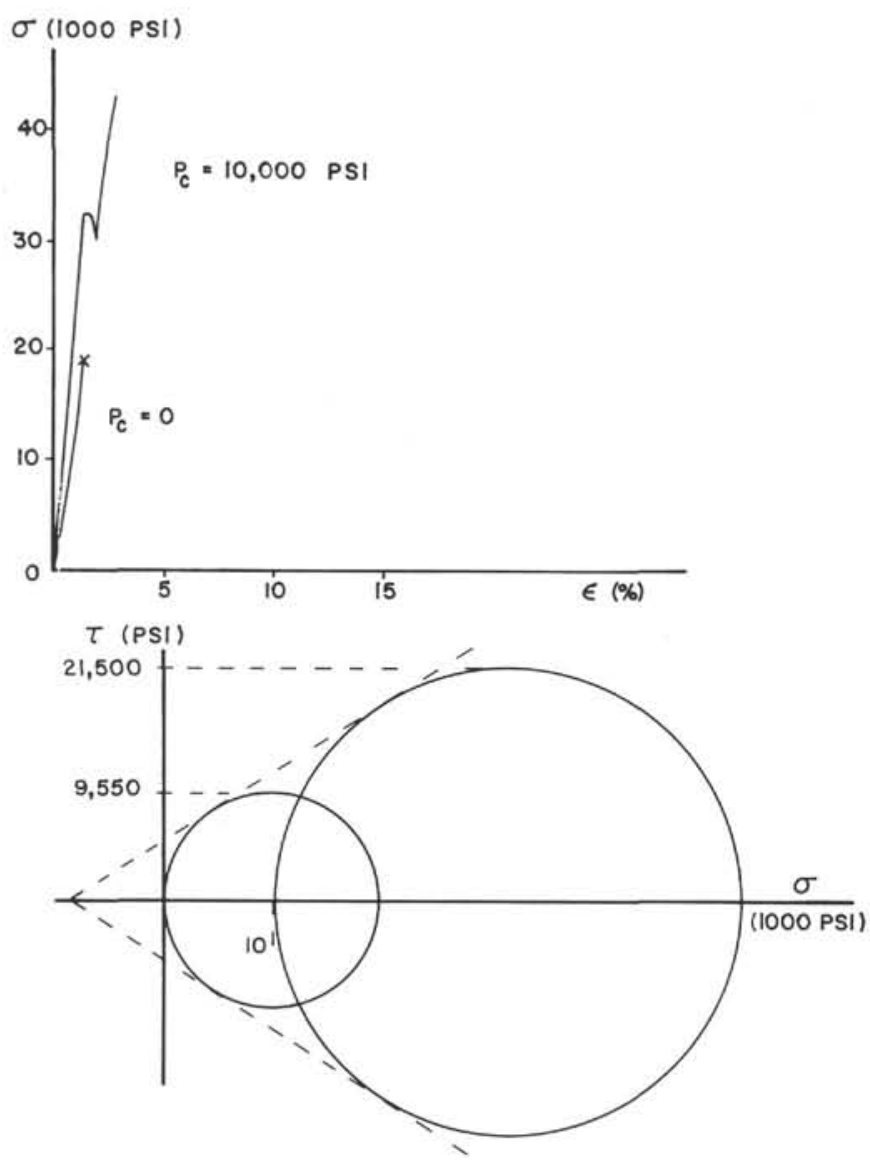

Figure 5. Stress-strain curves, Sample No. 199-10-2, No. 22.

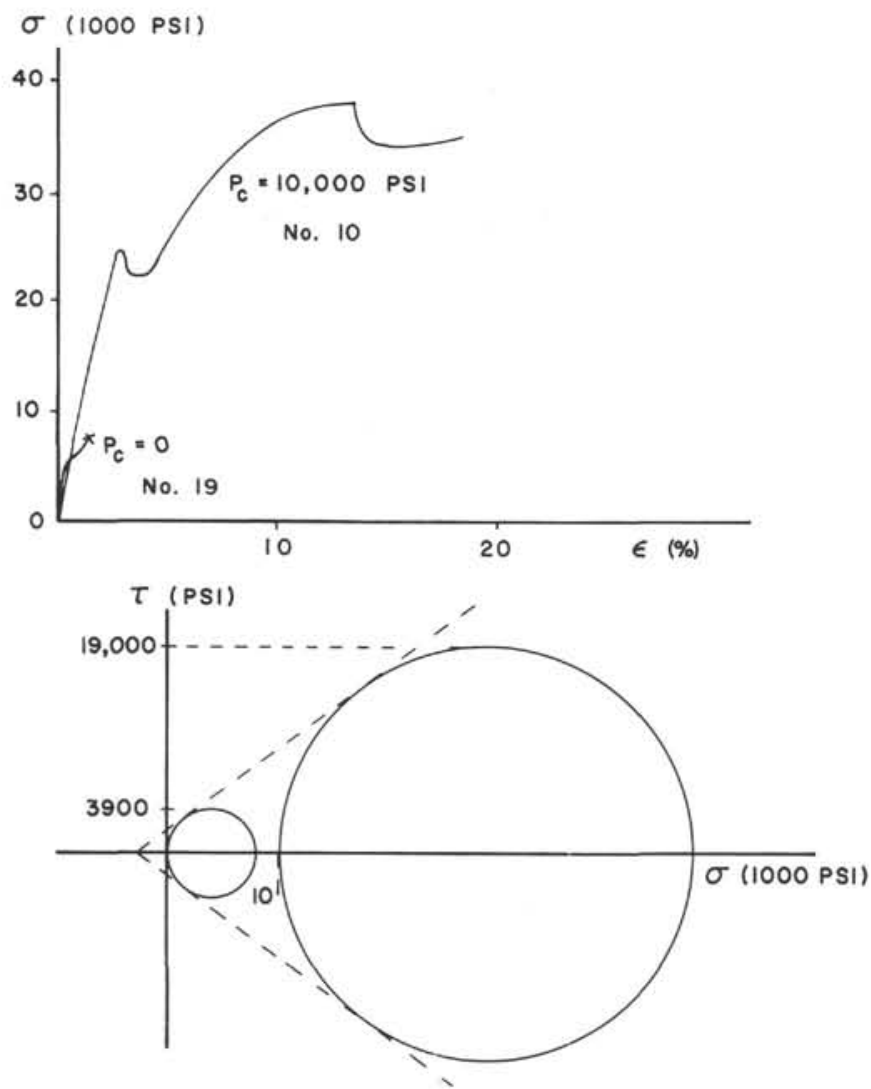

Figure 6. Stress-strain curves, Sample No. 197-1-1, No. 19 and No. 10.
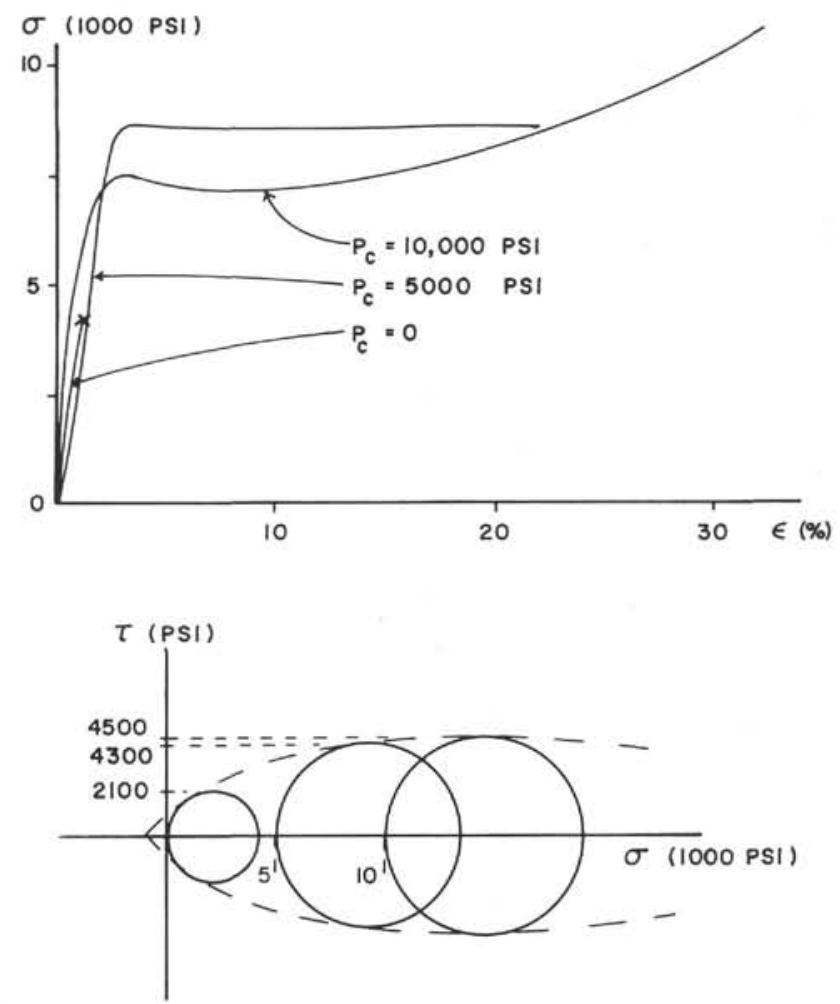

Figure 7. Stress-strain curves, Sample No. 199-1-2, No. 60.
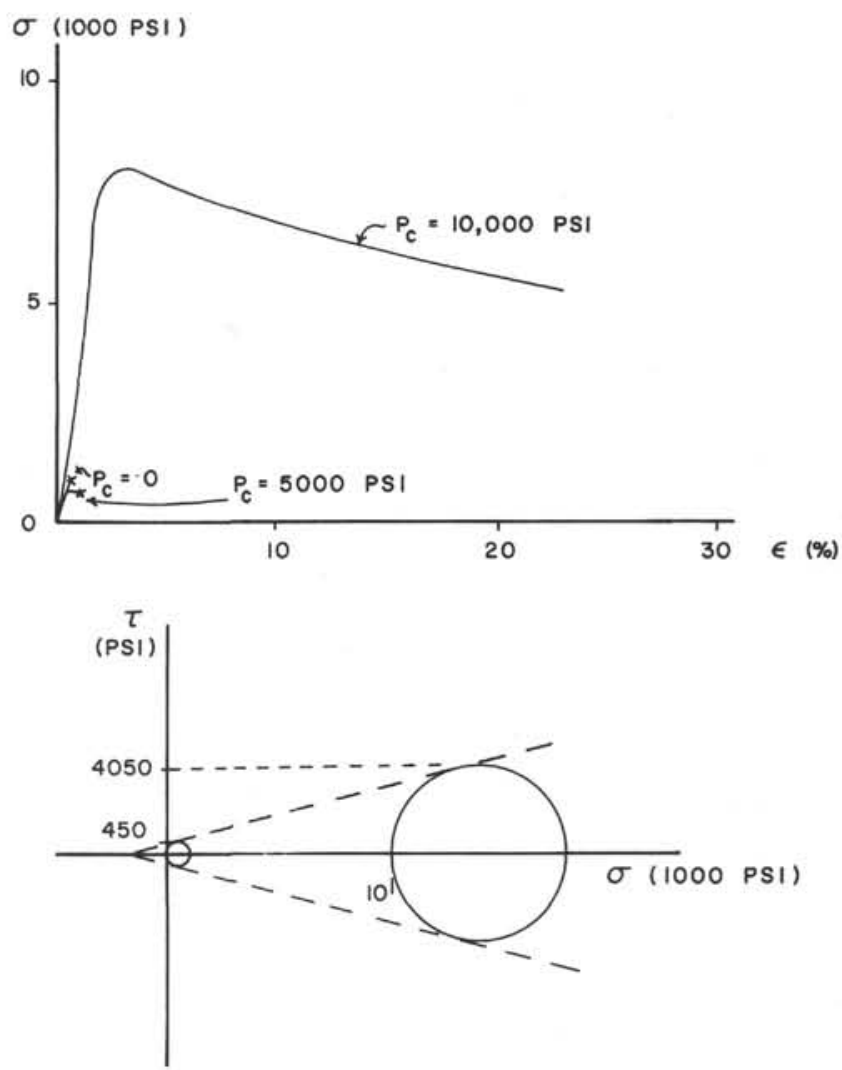

Figure 8. Stress-strain curves, Sample No. 202-3-CC, No. 14. 


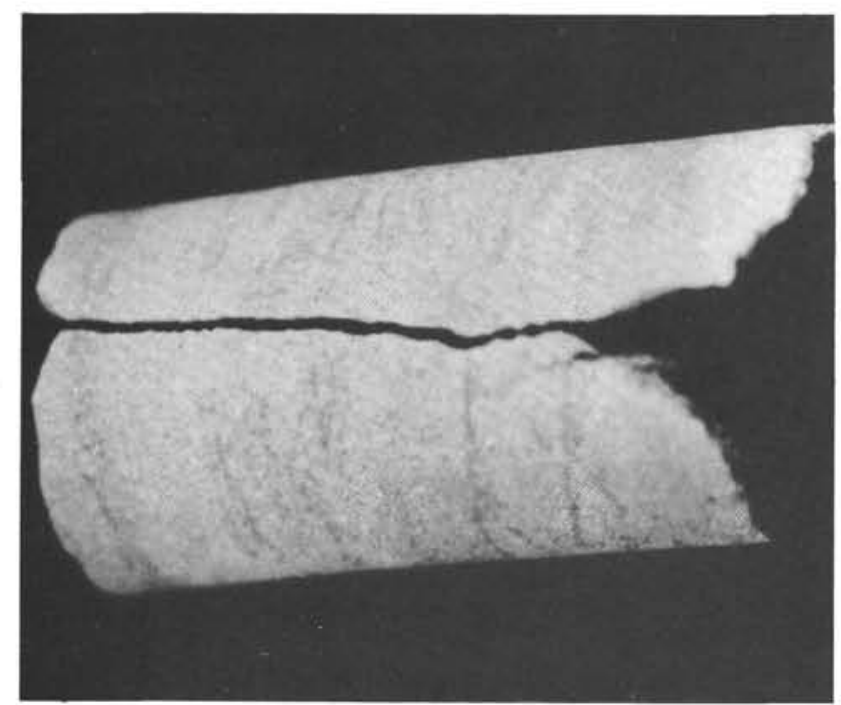

Figure 9. Sample No. 199-11-2, No. 60, tested at atmos. pheric confining pressure.

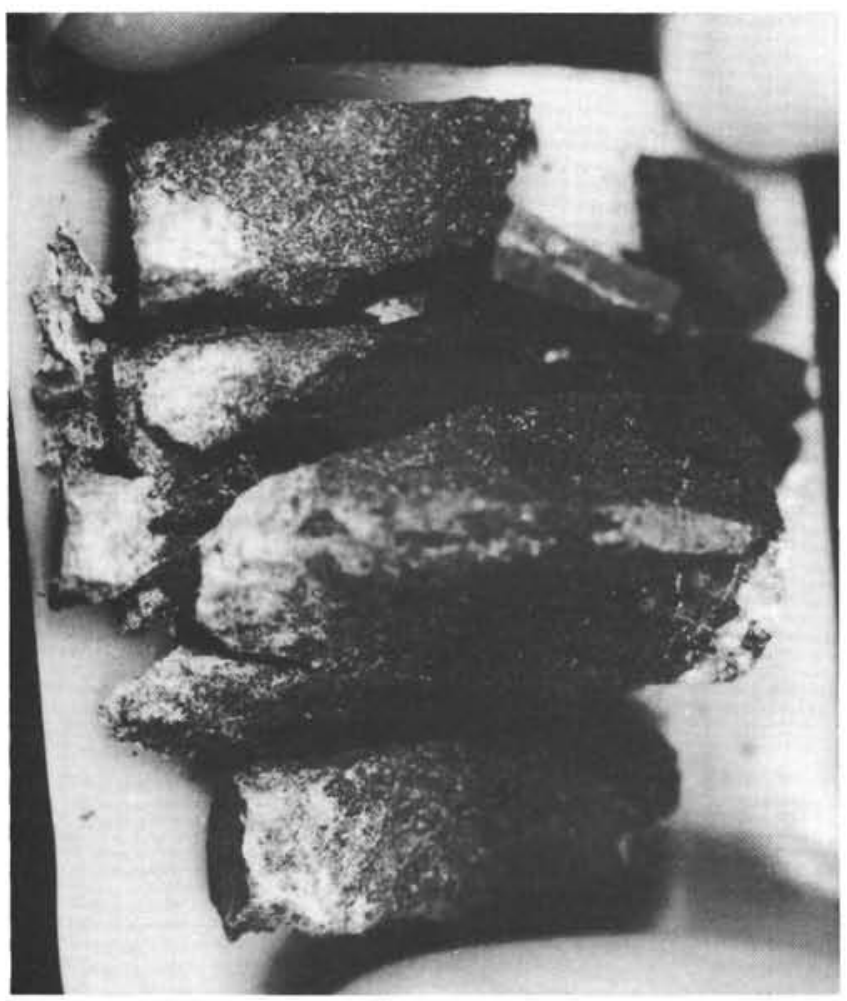

Figure 10. Sample No. 197-1-1, No.10, tested at atmospheric confining pressure.

Figure 11, which shows a sample of limestone tested at 5000 psi. At still higher confining pressures, more ductile deformation takes place. In Figures 12 and 13 gliding planes are visible on the surfaces of chalk tested at 10,000 psi.

At such high pressures, even chert becomes ductile, as shown in Figure 14. It is interesting to contrast the ductile behavior of cherts in laboratory tests with the usually brittle fractures caused by the drill bit beneath 6000 meters

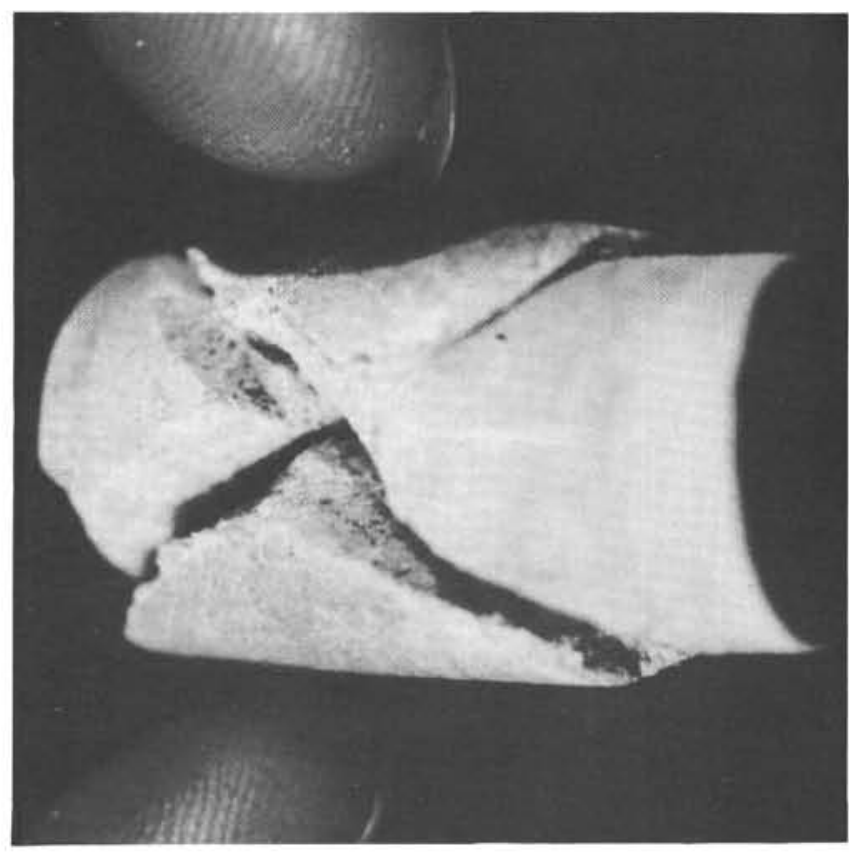

Figure 11. Sample No. 199-11-2, No. 60, tested at 5000 psi confining pressure.

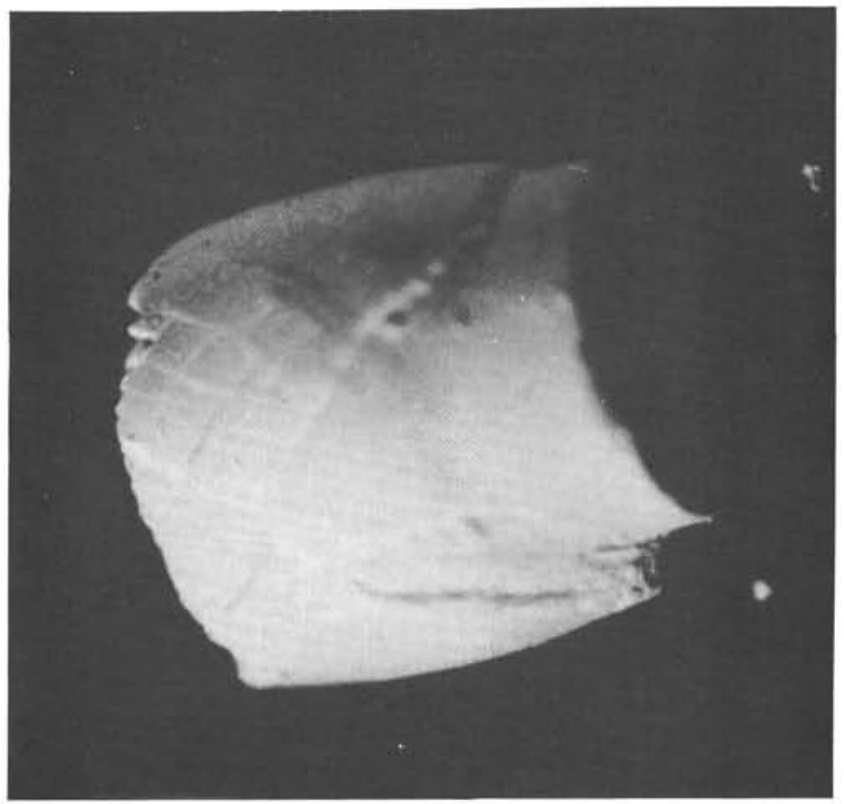

Figure 12. Sample No. 199-9-2, No. 13, tested at 10,000 psi confining pressure.

of water. The most likely explanation for the in situ brittle fracture is that the pore pressure is almost as high as the confining pressure, even though the rock has a low porosity, and thus the effective confining pressure is very small.

\section{ACKNOWLEDGMENTS}

We thank Robert Tan and John Cheatham for their help in performing the tests. 
TABLE

\begin{tabular}{|c|c|c|c|c|c|c|}
\hline \multicolumn{2}{|c|}{ Sample No. } & $\begin{array}{c}\text { Confining Pressure Pc } \\
\text { (Psi) }\end{array}$ & $\begin{array}{c}\text { Initial Yield Strength } \\
\text { (2\% Strain) }\end{array}$ & $\begin{array}{c}\text { Maximum Strength } \\
\text { (Psi) }\end{array}$ & Ductility & $\begin{array}{c}\text { Maximum Strain } \\
(\%)\end{array}$ \\
\hline $199-7-1$ & No. 1 & 10,000 & 7,100 & $12,500_{1}^{1}$ & ductile & $30^{\mathrm{a}}$ \\
\hline $199-7-1$ & No. 1 & 5,000 & 7,400 & $12,750^{1}$ & ductile & $38^{\mathrm{a}}$ \\
\hline $199-7-1$ & No. 1 & 0 & - & 2,088 & brittle & 1 \\
\hline $196-3-1$ & $\begin{array}{l}\text { No. } 7 \\
\tan \end{array}$ & 10,000 & 4,730 & $15,025^{1}$ & ductile & $44^{\mathrm{a}}$ \\
\hline $196-3-1$ & $\begin{array}{l}\text { No. } 7 \\
\tan \end{array}$ & 5,000 & 9,000 & $16,830^{1}$ & ductile & $38^{\mathrm{a}}$ \\
\hline $196-3-1$ & $\begin{array}{l}\text { No. } 7 \\
\tan \end{array}$ & 0 & - & 1,275 & brittle & 1 \\
\hline $199-9-2$ & No. 13 & 10,000 & 4,030 & $9,675^{1}$ & ductile & $37^{\mathrm{a}}$ \\
\hline $199-9-2$ & No. 13 & 5,000 & 3,760 & $6,825^{1}$ & ductile & $29^{\mathrm{a}}$ \\
\hline $199-9-2$ & No. 13 & 0 & - & 1,550 & brittle & 1 \\
\hline $195-3-1$ & brown & 10,000 & 24,700 & 33,150 & ductile & $24^{\mathrm{a}}$ \\
\hline $199-10-2$ & No. 22 & 10,000 & - & $32,275^{2}$ & brittle & $1.5^{\mathrm{b}}$ \\
\hline $199-10-2$ & No. 22 & 0 & - & $19,100_{2}$ & brittle & 1.5 \\
\hline $197-1-1$ & No. 10 & 10,000 & 24,430 & $38,100^{3}$ & ductile & $14^{\mathrm{c}}$ \\
\hline $197-1-1$ & No. 19 & 0 & - & 7,840 & brittle & 1.5 \\
\hline $199-11-2$ & No. 60 & 10,000 & 7,450 & $10,440^{1}$ & ductile & 30 \\
\hline $199-11-2$ & No. 60 & 5,000 & 8,650 & 8,650 & ductile & $23^{\mathrm{a}}$ \\
\hline $199-11-2$ & No. 60 & 0 & - & 4,225 & brittle & 1 \\
\hline $199-3(\mathrm{CC})$ & No. 14 & 10,000 & 8,100 & 8,100 & ductile & $23^{\mathrm{a}}$ \\
\hline $202-3(\mathrm{CC})$ & No. 14 & 5,000 & - & 713 & brittle & 1 \\
\hline $202-3(\mathrm{CC})$ & No. 14 & 0 & - & 916 & brittle $_{\mathrm{d}}$ & 1 \\
\hline $199-10-2$ & No. 12 & & & & brittle $\mathrm{d}^{\mathrm{d}}$ & \\
\hline
\end{tabular}

\footnotetext{
${ }^{\mathrm{a}}$ Test terminated before fracture.

${ }^{b}$ Sample appeared to fracture but then recovered and the stress continued to increase, apparently elastically; a maximum strength of $43,000 \mathrm{psi}$ was reached where the test was terminated. See remarks for possible explanation.

${ }^{\mathrm{c}}$ Sample appeared to fracture at $\sigma=38,100 \mathrm{psi}$ and about $14 \%$ strain but then recovered and continued to strain, reaching a final maximum strain of $18 \%$ and stress of 34,900 psi when the test was terminated. See remarks for possible explanation.

${ }^{d}$ Sample failed under hydrostatic pressure.
}

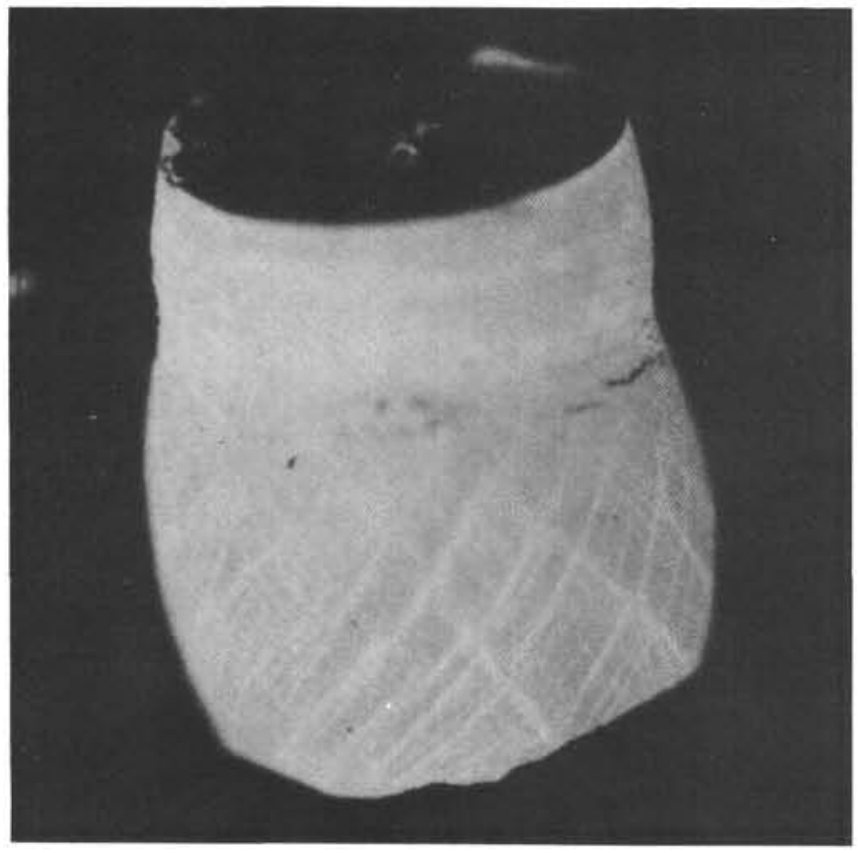

Figure 13. Sample No. 199-7-1, No. 1, tested at 10,000 psi confining pressure.

\section{REFERENCES}

Hardin, J., 1966. Strength and Ductility. In Clark, S.,P. (Ed.). Handbook of Physical Constants, Geol. Soc. Am. Terzaghi, K., 1943. Theoretical Soil Mechanics. New York (John Wiley \& Sons).

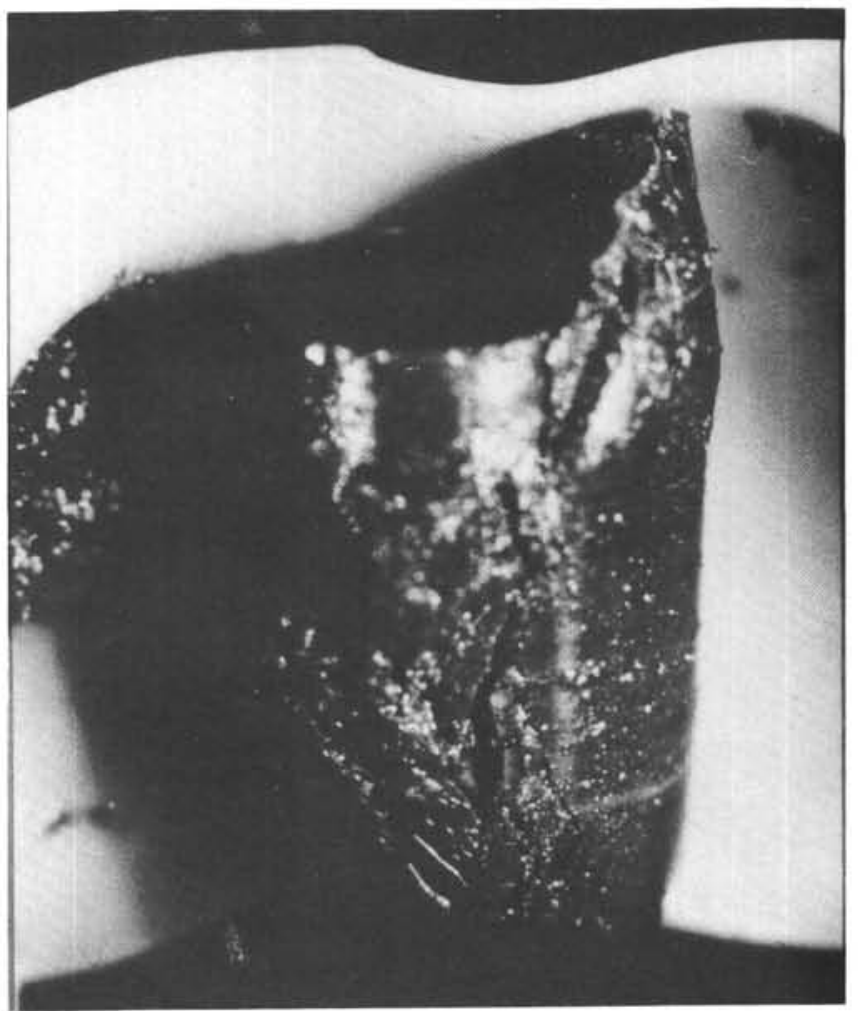

Figure 14. Sample No. 195-3-1, No. 1, tested at 10,000 psi confining pressure. 